\section{IN THE NEWS}

\section{Holding back hunger}

Scientists have discovered

two appetite-suppressing substances that could be

used to create anti-obesity drugs.

In the New England Journal of Medicine, Professor Bloom and colleagues showed that increasing the levels of the gut-hormone-fragment peptide $\mathrm{YY}_{3-36}(\mathrm{PYY})$ reduces appetite and calorie intake in lean and overweight people. The team also showed that "obese people have, on average, only two thirds the levels of [PY], made in their intestines, compared with lean people" (Daily Telegraph, 4 September 2003). These data indicate that a PYY

deficiency could contribute to the pathogenesis of obesity. In addition, Bloom said, "These findings suggest that boosting [PY] offers a novel approach towards treating the epidemic of obesity in our society" (Daily Telegraph, 4 September 2003).

In Nature, Professor Piomelli and co-workers reported that the fatty acid

oleylethanolamide (OEA) by activating the nuclear receptor peroxisomeproliferator-activated

receptor- $\alpha$ - is also involved in regulating hunger and metabolism. They

"discovered that by increasing OEA levels while maintaining normal levels of these cell receptors, they could reduce appetite and weight in rodents" (Science Daily,

4 September 2003).

So, these studies have identified natural compounds that could potentially be used to create anti-obesity drugs. However, Dr lan Campbell, chairman of the National

Obesity Forum, urges caution. "If this does lead to the development of even better drugs, it must be welcomed. But I am conscious that we have been here before and that other wonder molecules have failed" (Daily Telegraph, 4 September 2003). "People have to modify their lifestyle. That's got to be the most important thing to do" (BBC News, 4 September 2003).

Rachel Smallridge

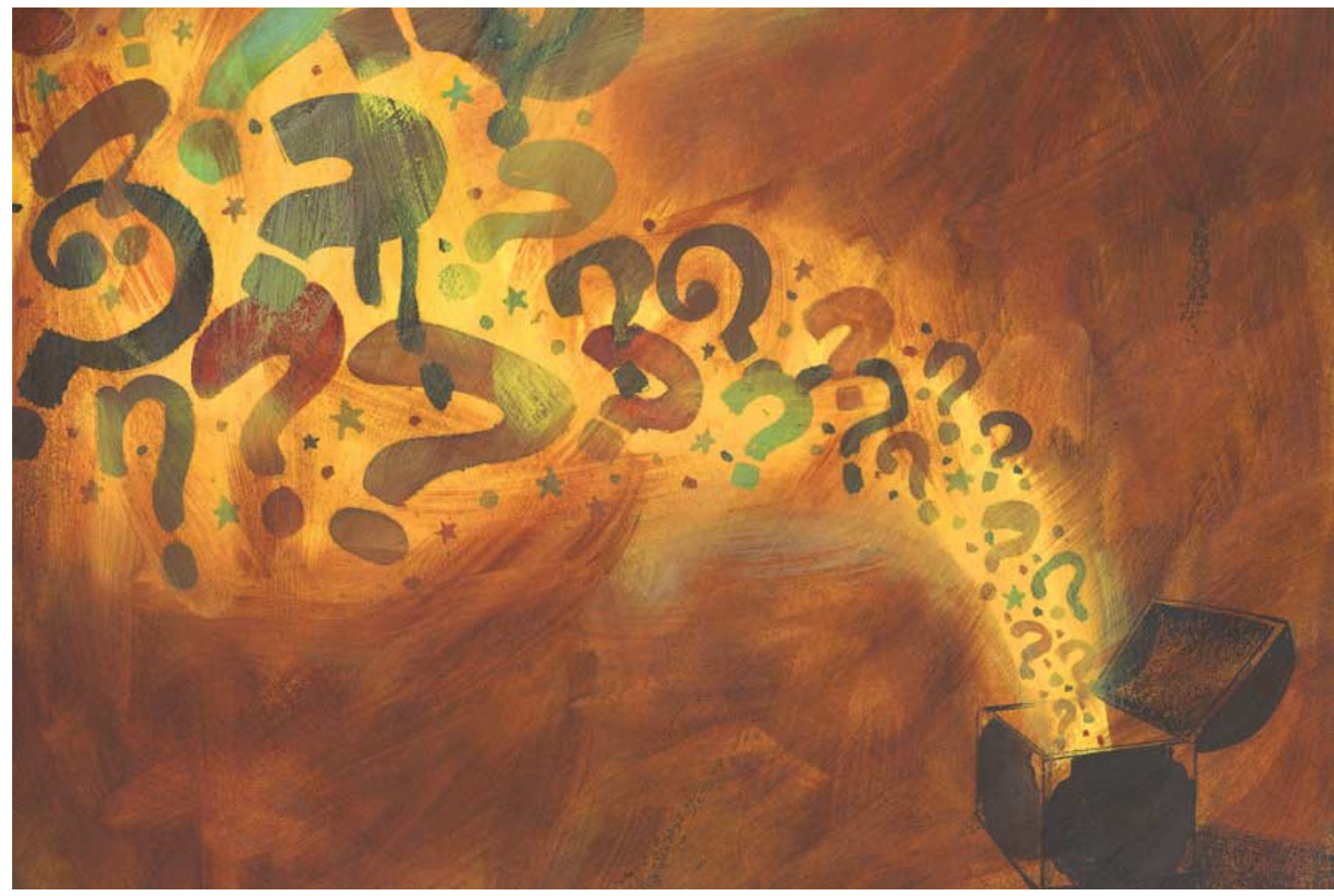

\section{CHROMOSOME BIOLOGY}

\section{The plot thickens}

How chromatin folds into mitotic chromosomes remains something of a mystery. The huge compaction of genomic DNA - by 10,000-fold - is thought to be largely controlled by a protein complex known as condensin. However, a report by Bill Earnshaw and colleagues in Developmental Cell now shows that condensin is dispensable for chromosome condensation, but that it does have an important function in promoting the association of nonhistone proteins with mitotic chromosomes. This structural role is essential for establishing a robust chromosome structure.

Earnshaw's group created a conditional knockout of ScII (also known as SMC2) — one of the subunits of condensin - in chicken cells. In the absence of ScII, chromosome segregation failed, but the chromosomes did condense, albeit more slowly than usual. Analysis of the kinetochores and mitotic spindles of the ScIIdeficient cells showed that condensin wasn't required for assembling a bipolar spindle or normal kinetochore structure and function.

So what is condensin's role? One possibility is that nonhistone proteins assemble into a structural network within chromosomes - a scaffold - upon which chromatin is arranged. One criticism of this model has been that nonhistone proteins might associate nonspecifically during chromosome extraction, but data from the Earnshaw group argue against this. Deletion of ScII caused topoisomerase II, the passenger protein INCENP (inner centromere protein) and at least 13 other proteins that are normally part of the scaffold to become soluble, so they concluded that scaffold components that are present in the condensincontaining fraction are there because of specific interactions. ScII, and therefore condensin, confers structural integrity by promoting correct associations between scaffold proteins.
To further investigate the role of condensin, the authors developed an assay that is based on a largely neglected study by Cole (1967), which showed that chromosomes are extremely resilient. Chromosomes can be exposed to buffer conditions that completely disrupt their higher-order chromatin structures, unfolding them right down to a nucleosomal 'beads-ona-string' filament, but, when returned to favourable conditions, their condensed morphology is restored. Earnshaw and colleagues showed that ScII is required for this structural memory, as ScII-deficient chromosomes were unable to recover their native morphology after extensive chromatin unfolding. These results seem to be at odds with models proposing that the organization of the chromosome is directed only by chromatin-fibre interactions.

Earnshaw and colleagues now present an updated model in which nonhistone proteins have an essential role in the structural integrity of chromosomes. Their observations are consistent with a model in which linking elements - 'anchoring complexes'- constrain the chromatin fibre, giving it a structural memory. The authors speculate that, within these complexes, condensin binds, forming a 'landing pad' for nonhistone proteins (for example, topoisomerase II and INCENP). Alternatively, condensin might alter the supercoiling or conformation of mitotic chromatin to promote localization and specific binding of nonhistone components. They also speculate that the anchoring complexes could be the true chromosome scaffold more like a network of small crosslinking complexes than a large integrated structure.

In conclusion, whereas condensin clearly has an important role in forming the condensed mitotic chromosome, another factor must be essential for condensation. The race is now on to identify this factor.

Maria Hodges, Nature Publishing Group

6) References and links

ORIGINAL RESEARCH PAPER Hudson, D. F. et al. Condensin is required for nonhistone protein assembly and structural integrity of vertebrate mitotic chromosomes. Dev. Cell 5, 323-336 (2003) FURTHER READING Cole, A. Chromosome structure. Theor. Biophys. 1 305-375 (1967) 